\title{
Goodman on Truth
}

\begin{abstract}
Nelson Goodman belongs to the camp of those philosophers who attempt to understand the concept of truth in epistemic terms - in such terms as verifiability, warranted assertibility, permanent acceptability, superassertibility or justifiability in ideal epistemic situations. Goodman's original proposal was to define truth as permanent credibility. Later, however, he weakened this claim and merely suggested that permanent credibility is a sufficient condition for truth. The author argues that an epistemic status is neither a necessary nor a sufficient condition for truth and thereby demonstrates that neither Goodman's nor any other epistemic conception of truth can work.
\end{abstract}

\section{I}

In the contemporary philosophical debate on the concept of truth, we can, with a certain simplification, distinguish two factions (cf. Schantz 1996, 2002). On the one hand, there are those philosophers who maintain that the concept of truth is an important, indispensable, a profound or substantial concept - in any case, a concept worth defending. Within this faction, we can further differentiate between those philosophers who have committed themselves to a realist view on truth from those who support an epistemic analysis of the concept. On the other hand, there are philosophers who assert that the advocates of the first faction suffer from a major delusion, that, in principle, they are chasing after a chimera when they assume that truth has some underlying nature that could be analyzed epistemically, ontologically, or semantically. The advocates of the second faction make the radical assertion that truth is not a substantial or explanatory concept, not a concept that expresses some interesting property or some interesting relation. On the contrary, in their view truth is a purely formal or logical concept, a concept whose correct explanation requires far less extravagant conceptual resources than adherents of substantive theories believe. Partisans of the second faction advocate a deflationary or minimalist analysis of truth (cf. Horwich 1990; Quine 1990). 
I advocate a realist conception that sees truth as a relationship between a truth bearer - a statement or belief - and a truth maker, a reality that has an objective status with respect to the truth bearer. Truth makers are familiar entities: objects having certain properties and standing in certain relations to each other at various spatiotemporal locations. Further, I think that truth can be explained by objective referential relationships between language and the thought expressed on the one hand and the external world on the other (cf. Schantz 1996, 2001a). Such a referential explication, then, allows us to develop a plausible form of the correspondence theory of truth that can take seriously the intuitive idea that a statement is true if and only if the fact or state of affairs actually obtains whose obtaining is asserted by the statement. Correspondence does not require something as pretentious as a relation of structural isomorphism between statements and facts, as early Wittgenstein und Russell once thought (Wittgenstein 1922; Russell 1912). Ordinary reference is enough.

The fact that tomatoes are red is both a necessary and a sufficient condition for the truth of the statement that tomatoes are red. It is true that $p$ if and only if $p$. Facts, as I see them, are not completely artificial, "sentenceshaped" objects, mere shadows cast by our linguistic practice of making statements, as Peter Strawson and Donald Davidson suggest (cf. Strawson 1950; Davidson 1990). And facts are not true thoughts either, as Frege (1919) contended. Rather, facts are components of the objective, mindindependent spatiotemporal world. Neither the existence nor the nature of facts depends, in any philosophically significant sense, on what we believe, think or perceive. Moreover, an essential element of the realist view is that truth transcends verifiability, that a statement can be true even though we, beings with our sensory and cognitive nature, are not at all able to verify it. Truth and objective reality cannot be reduced to what we are able to ascertain. Truth, according to alethic realism, is evidence-transcendent; it exceeds rational acceptability (cf. Schantz 1996).

\section{II}

It is well-known that Nelson Goodman belongs to the sharpest critics both of the correspondence theory of truth and of alethic realism in general. In fact, he is opposed to the prevailing tendency to overestimate the scope and 
the philosophical significance of the concept of truth. According to him, truth is just one species of a more general and more important virtue he calls "rightness" ( $W W, 1-22)$. Whereas truth applies only to statements, rightness comprises all standards of acceptability of linguistic and nonlinguistic symbol systems. So works of art, pictures and symphonies, e.g., also constitute versions of the world, and are the bearers of semantic properties. Both scientific and artistic symbol systems have a cognitive function. They do not just mirror aspects of the world, but are, rather, productive forms of representation.

It is one of Goodman's central ideas that there is no such thing as a unique right version of the world. There is, rather, a plurality of incompatible and yet right versions. He likes to illustrate his point with geometrical examples. Points, for example, can be identified with sets of concentric spheres or, alternatively, with intersections of three planes. One can also invoke examples from physics. In Newtonian physics, physical events can be reduced either to particles acting at a distance, across empty space, or to particles interacting locally with electro-magnetic fields.

Here we seem to have two incompatible theories about the world. For either there are or there aren't fields which mediate the action of separated particles on each other. Relative to field theory, the statement "There are fields" is true, relative to its competitor, the particle theory, however, this statement is false. That is, apparently, what the theory-relativity of this statement consists in. The question whether there really are electromagnetic fields does not seem to have a theory-independent answer. Therefore, it is tempting to reject the question which of the two theories is really true as a metaphysical pseudo-problem. Both theories, so Goodman would claim, can be simultaneously true. After all, they are empirically and mathematically equivalent; they are mathematically intertranslatable.

Surprisingly, Goodman's conviction that there is no unique right version of the world is accompanied by the idea that we do not live in one world but in many different worlds at the same time. And these worlds, he contends, are real worlds, not the merely possible worlds that fans of the semantics of possible worlds go into raptures about $(M M, 31)$. Moreover, he even maintains, in a manner reminiscent of Fichte's and Hegel's idealism, that we have made these worlds - not, of course, ex nihilo, but out of previous worlds. According to Goodman, there is no ready-made 
world, no world dictating its only true description. So he defends pluralism against monism, antirealism against realism, and a form of relativism against absolutism - a form of relativism, however, that retains the difference between rightness and falsity and hence discards the principle that "everything goes".

Israel Scheffler (1980) has drawn attention to an important ambiguity in Goodman's use of the key expression "worlds". Sometimes Goodman uses this expression simply to mean versions; this is a "versional" use with "versional reference". The pluralism resulting from this use resumes the commendable and fruitful doctrine, developed already in the Structure of Appearance, that all prephilosophical subject matters can be systematized in ways that conflict with one another. Elsewhere, however, he means by "worlds" objects that the versions refer to or describe. This "objectual" use with "objectual reference" includes: "the many stuffs - matter, energy, waves, phenomena - that worlds are made of." $(W W, 6)$ Goodman himself gives emphasis to the weighty difference between versions with reference and versions without reference $(W W, 96)$. "Don Quixote" and "unicorn" are empty terms, terms without any referential function. "Stephen Hawking" and "planet" possess referential functions; by using them we refer to existent things. It is important to distinguish between these two senses of "world". For surely, as Scheffler grants, by using symbols we make worlds in the sense of versions, but it does not follow therefrom that we also make the worlds to which these versions refer. It is indeed we who make world versions, but it is not we who make these versions true or right, or who make the terms they contain into non-empty, referential terms.

Goodman concedes the ambiguity in the use of "world" diagnosed by Scheffler $(M M, 119)$. His answer is that, although the versional and the objectual interpretation conflict with one another, they are both right and often exchangeable. He does admit that versions are not worlds; after all, some versions consist of words, but their worlds do not. Nonetheless he insists that worlds depend on versions because, as he expounds, the true versions make worlds. But he still owes us a really satisfying explanation of how in making versions we also make worlds. In the end, for Goodman, in contrast to Scheffler and the point of view of reflected common sense, there is no significant difference between regarding true versions as 
descriptions of worlds, or supposing instead that there are no worlds at all but only versions. He does not attach great importance to ontological or metaphysical statements of a problem. So he writes:

The realist will resist the conclusion that there is no world; the idealist will resist the conclusion that all conflicting versions describe different worlds. As for me, I find these views equally delightful and equally deplorable - for, after all, the difference between them is purely conventional $(W W, 119)$.

In keeping with his anti-metaphysical stance, he designates his position not as "antirealism" but rather as "irrealism". By employing this label he does not want to give expression to the view that everything or even anything is unreal, but that the whole dispute between realism and antirealism is undermined by the insight that the boundary between convention and content is arbitrary and variable.

In his counter-move Goodman challenges Scheffler to specify an aspect of the world, e.g. of stars, that is independent of all versions or discourses. I share with Scheffler the unwavering persuasion that we did not ourselves make the stars and their physical properties. We have, by creating and shaping our language, also created the concept star with its, as must be admitted, partly conventional boundaries. Our language cannot be neatly divided into two parts, one part describing the world as it is in itself, and the other part describing our conceptual contribution. But from the fact that the concept star comprises conventional elements it does not follow that we are responsible for the concept's being true of certain things, or that we have made those things. The discourse-dependence of the concept star by no means implies that the stars themselves are discourse-dependent. Obviously, we cannot describe the world independently of our versions. But we should take care not to draw from this truism the absurd conclusion that there are only versions or discourses in the end. His incontestable philosophical brilliancy and the acumen of many of his argumentations cannot protect Goodman from manoeuvring himself, with several of his formulations, into dangerous closeness to Jacques Derrida's project of deconstruction. I wished we could overlook his idealist jargon as mere rhetoric. But Goodman explicitly denies this. 


\section{III}

This is, roughly sketched, the background against which Goodman rides his attacks against the correspondence theory and against the apparently closely allied doctrine of metaphysical realism. In Ways of Worldmaking he says:

We cannot test a version by comparing it with a world undescribed, undepicted, unperceived, but only by other means ... all we learn about the world is contained in right versions of it; and while the underlying world, bereft of these, need not be denied to those who love it, it is perhaps on the whole a world well lost $(W W, 4)$.

According to Goodman, we can compare a version only with other versions, not with the world itself. When we compare our theories with sensory data, we compare them with that version of the world that experience is presenting us. In his eyes, experience is not a simple, unvarnished givenness but itself the product of a process of interpretation regulated by theory and by culture $(W W, 92-93)$.

I think, however, that his assumption that the correspondence theory requires a comparison with naked, unconceptualized reality is pretty implausible. Why should an advocate of the correspondence theory not be able to describe, to conceptually articulate, the facts that make our statements true? The statement that tomatoes are red corresponds to the fact that tomatoes are red which I have just described by using the words "tomatoes" and "red".

It is clear, however, that Goodman's critique of the correspondence theory is epistemologically motivated. What he seems to miss in this theory is a useful test or an effective criterion of truth. After all, we also want to know whether the statements we make and the beliefs we hold are true or false. And he is deeply convinced that the correspondence theory cannot succeed in establishing our cognitive access to reality. For there is, according to his central objection, that in similar forms has also been raised by the Logical Empiricists Neurath and Hempel, and, more recently, by Davidson (1986, 307), Putnam (1983, VII) and Michael Williams (1977, 112), no pure, unmediated consciousness of external objects or facts as they are in themselves, independently of our ways of conceptualizing them. Therefore, we cannot compare our statements and beliefs - our linguistic and nonlinguistic representations - with the world itself in order to see 
whether they agree or correspond with it. The alleged comparison of a belief with raw reality finally turns out to be merely a comparison of a belief with other beliefs. We cannot break out of the circle of our beliefs to get hold of the objective reality itself. Hence beliefs, so runs the conclusion, can only be justified by the internal coherence in a system of beliefs.

This popular objection overlooks the epistemological neutrality of the correspondence account. This account tries to tell us only what the nature or essence of truth is. It does not pretend to provide a criterion of truth telling us how to find out what is true and what is false. Nevertheless, I think it is worthwhile to throw a short, critical glance at this influential objection which attempts to show that the correspondence theory leads to epistemological skepticism in the end because it implies that objective facts are beyond our cognitive ken. I have scrutinized and rejected this argument elsewhere and defended the intuitive standpoint that we are indeed capable of comparing our beliefs with the facts (cf. Schantz 1999, 2001b). Why is such a comparison supposed to be impossible? I have found no compelling reason for this supposition. Indeed I think that no mysterious feat is required for comparing our beliefs with the world. All that is required are commonly accepted methods for acquiring knowledge. So we have, under standard conditions, through perception a direct cognitive access to external facts, an access that enables us to ascertain whether or not these facts render our beliefs true. But the directness or immediacy is not really essential. To determine whether the statement that $p$ corresponds to a fact we just have to determine whether $p$ - no matter how, whether directly or by more or less indirect routes, such as inference to the best explanation. Thus the correspondence theory by no means leads to the absurd conclusion that beliefs and judgments are the only things to which we have a cognitive access.

Goodman, however, thinks otherwise. His credo is coherence instead of correspondence or confrontation. And surely, the internal coherence of our beliefs is of crucial importance to the theory of epistemic justification. In this context, Goodman rightly emphasizes that coherence alone is not sufficient to determine truth, but has to be supplemented by judgments that express an "initial credibility" $(W W, 125)$. But, in my opinion, the theory of epistemic justification is one thing, and the definition or analysis or 
theory of truth is another. I myself defend a correspondence theory of truth and a theory of justification according to which both the coherence of our versions and sensory experience are relevant to the warrant of our beliefs (cf. Schantz 1996, 1999, 2001b).

Goodman is of a different opinion. He thinks that truth and test of truth cannot be separated from each other at all. He even goes so far as to contend: "Truth, like intelligence, is perhaps just what the tests test; and the best account of truth may be an 'operational' one in terms of tests and procedures used in judging it" ( $W W, 122)$. Hence he seems to have some kind of an epistemic analysis of truth in mind. In his reply to Hilary Putnam's fervent commentary on Ways of Worldmaking he speaks of: "my suggestion that truth might be equated with permanent credibility" (Goodman 1980, 211), and elsewhere he recommends ,construing truth as ultimate acceptability: as acceptability that is not subsequently lost“ (Goodman 1982, 359).

Goodman seems to join the camp of those philosophers who support an epistemic analysis of truth, an analysis which tries to elucidate the concept of truth by an epistemic conceptual repertoire, that is, by such concepts as permanent credibility, verifiability, warranted assertibility, superassertibility or justifiability under ideal conditions. According to the point of view of alethic antirealism, truth consists, roughly speaking, not in a relationship to an external fact, but rather in the positive epistemic status of the truth bearer within our language, our thought or our experience.

\section{IV}

Putnam, and already much earlier Carnap, have shown that truth cannot be simply identified with verification or justification (cf. Putnam 1981, 55; Carnap 1936). Against this simple-minded identification the convincing reason can be brought to bear that truth is a stable property of statements, a property that cannot be lost, whereas justification is tensed and therefore can be lost. The statement "The earth is flat" was, most probably, justified 3,000 years ago, but it is no longer justified today. It would, however, be wrong to say that the statement "The earth is flat" was true 3,000 years ago, for that would mean that the earth has fundamentally changed its shape in the meantime. The conclusion we have to draw from this is that 
truth cannot be simply equated with justification. Of course, Goodman is well aware of this objection and tries to dispel it in the following way:

Consider for a moment the notion of permanence - taken here to mean lasting forever after some given time. Although we can never establish permanence of an object or material, we can establish durability in varying degrees short of permanence. Likewise, although we can never establish total and permanent credibility, we can establish strength and durability of credibility in varying degrees short of that. Shall we then identify unattainable total and permanent credibility with unattainable truth? To the ready protest that we might have total and permanent belief in falsehood - that what is totally and permanently credible might not be true - perhaps the answer is that so long as the belief or credibility is indeed total and permanent, any divergence from the truth could not matter to us at all. The proposal seems to be that if there is any such divergence, so much the worse for truth: scrap it in favour of total and permanent credibility, which though equally unattainable is explicable in terms of what is attainable, just as permanence is explicable in terms of durability $(W W, 123-124)$.

Hence we should, so runs Goodman's radical proposal, throw the concept of truth overboard, if it diverges from permanent credibility. A quite similar conception of truth has been later developed by Crispin Wright - without, however, mentioning Goodman. Wright suggests that the best way to capture the spirit of the pragmatist conception of truth is to conceive it globally as "superassertibility". According to him, a statement is superassertible just when it is enduringly justified or, a bit more precisely: a statement is superassertible if and only if it is justified by some accessible state of information and will remain justified no matter how that state of information is enlarged upon or otherwise improved (cf. Wright 1992, 44-57).

Goodman's and Wright's proposals can, however, be refuted by considering cases of the following kind, which figure prominently in current discussions about indefeasibility theories of knowledge (cf. Skorupski 1988). Suppose that, under standard conditions of perception, I see Mary, whom I know pretty well, and that, on this stable evidential basis, I am completely warranted in asserting that it is Mary whom I see. Imagine now, however, that Mary's mother tells me that Mary is not in town today, but that her qualitatively identical twin sister Anna, whom she herself often confuses with Mary, is in town. This new information defeats my warrant. Suppose further that, quite unknown to me, what Mary's 
mother said was quite wrong - perhaps because she was in a state of bewilderment. By virtue of the increment to my original state of information, the statement that I see Mary is no longer superassertible. But it is true nonetheless. So a true statement need not be superassertible or permanently credible. Hence we are well advised not to scrap the intuitive concept of truth.

In his book Of Mind and Other Matters, which appeared in 1984, Goodman himself has abandoned the view that permanent credibility or ultimate acceptability is a necessary condition for truth. Those passages in the texts reprinted here which seemed to point in this direction were appropriately revised. Unfortunately, he does not even mention his change of mind, and hence he also remains silent about the reasons for it. Instead, he now proclaims: "Ultimate acceptability - acceptability that is not subsequently lost - serves as a sufficient condition for truth ..." $(M M, 38$; cf. also 40), and he accentuates that he does not propose to define truth as ultimate acceptability (ibid.).

In the meantime Goodman himself seems to have come upon some of the serious problems that an epistemic analysis of truth is confronted with. Nonetheless, he still adheres to the assertion that permanent credibility is at least a sufficient condition for truth. We will come back to this point soon.

\section{$\mathrm{V}$}

First, however, I want to ask the question of whether there are not other, perhaps more promising theoretical approaches to understanding the concept of truth in epistemic terms.

In my opinion, the conception of truth which Putnam advocated during his internal-realist phase, the conception of truth as justifiability under epistemically ideal conditions, i.e., under conditions in which all relevant facts are available, has been the most interesting, fruitful, and informative attempt thus far to definitively bridge the logical gap between truth and justification. Putnam characterizes his internalist concept of truth in the following way:

"Truth", in an internalist view, is some sort of (idealized) rational acceptability - some sort of ideal coherence of our beliefs with each other and with our experiences as those experiences are themselves represented in our belief system - and not correspondence 
with mind-independent or discourse-independent "states of affairs" (cf. Putnam 1981, 49-50).

Putnam's theory, which equates truth with an idealization of rational acceptability or, using John Dewey's term, of "warranted assertibility", incorporates essential elements of both coherence theories and pragmatist theories of truth. Moreover, Putnam likes to lay emphasis on the affinities to Kant's equally epistemically constrained conception of truth (cf. Putnam 1981, 60-64). Yet, he attributes the main idea behind his new view to the antirealist philosophy of Michael Dummett. For here he felt that he had found a coherent alternative to both the correspondence theory and the redundancy theory of truth (cf. Putnam 1978, 127-130; 1983, XVI, 81-86). Expressed somewhat simplistically, Dummett's view is that the meaning of a sentence is not provided by its realist, recognition-transcendent truth conditions, but, instead, by its verification conditions (cf. Dummett 1975 and 1976).

Even though he ascribed his rejection of the correspondence theory to Dummett's increasing influence on his position, Putnam immediately began to emphasize that there were essential differences between his own view and that of Dummett. For the most part, these differences of opinion are related to Putnam's much greater concern with the differences between mathematical discourse - an important source of inspiration for Dummett's semantic approach - and empirical discourse. Consequently, Putnam was much more careful than Dummett in applying verificationist semantics to empirical discourse.

Dummett equates truth with justification tout court. Whereas he originally understood "justification" largely in the restrictive sense of conclusive justification, he later began to use the term in a weaker sense, meaning a justification of the strongest available kind (cf. Schantz 1996, 240-46). Putnam is very skeptical about the idea that statements about external material objects can be conclusively justified (cf. Putnam 1983, XVI-XVIII, 22). A mathematical statement is either proven or not. But in areas beyond mathematics, in the realm of contingency, we are hardly in a position to fully exclude the possibility of error. Putnam reminds us that in the empirical sciences, verification is always a matter of degree. In stark contrast to Dummett, Putnam is a staunch epistemological holist. There is such a thing as a formal proof of an isolated mathematical theorem. But - and Putnam 
insists on this point no less than Willard Van Quine - the unity of verification in the empirical sciences is the entire theory and not an isolated statement. The sentences of a theory are not separately vulnerable to adverse observations, because it is only jointly as a theory that such sentences imply their observable consequences.

Putnam's main objection, however, aims at Dummett's suggestion of simply equating truth with justification (cf. Putnam 1981, 55; Putnam 1983, 84-6). As pointed out above, truth is stable, whereas justification is tensed.

\section{VI}

I think that Putnam actually succeeded in eliminating various flaws of earlier, much more radical approaches. It is also important to note that Putnam explicitly dissociates himself from Peirce's suggestion that there is such a thing as an epistemic situation which is simultaneously ideal for the justification of every true statement. Rather, Putnam insists that the question of what are better or worse epistemic situations varies from statement to statement (cf. Putnam 1990, VIII). So the notion of ideal epistemic conditions must be specialized to the topic at issue. Nevertheless, I will now demonstrate that his own epistemic definition is also not able to stand up to a critical examination.

First of all, strikingly enough, Putnam makes no serious attempt to define the notion of epistemically ideal conditions more precisely. Certainly, this is no easy task, for specifying the details of such conditions would require stating one's position on fundamental epistemological problems. Thus, it can be expected that the distinct views of internalists and externalists on the one hand and of fundamentalists and coherentists on the other result in varying criteria of what an epistemically ideal situation actually is. In any case, Putnam clearly interprets an epistemically ideal situation in an anthropocentric way - as a situation that is ideal for $u s$, for finite entities with our perceptual and cognitive faculties. Other possible creatures that may have cognitive abilities far beyond our own rightly remain overlooked. Of course, the reason why epistemic definitions of truth are motivated by an anthropocentric position is obvious: they are to demonstrate that truth is accessible to $u s$, so that, in principle, truth cannot transcend the evidence that we can attain for it. Within this context, it is apparent that any omniscient 
creature is of no avail. Without any qualification whatsoever, realism can readily acknowledge that for a statement to be true it is a necessary condition that an omniscient creature would accept the statement.

But it is precisely this restriction to cognitive human subjects that makes epistemic analyses vulnerable to the objection that there could be true statements that are not justifiable for us in an epistemically ideal situation. Even in such a situation, they might be unjustifiable for us because the reasons that tell for their truth might remain, in principle, inaccessible to us due to our sensory and cognitive limitations. And, in an analogous way, false statements might be justified for us in an epistemically ideal situation because the reasons that tell against their truth might be, in principle, inaccessible to us. It becomes evident that justifiability under epistemically ideal conditions is neither a necessary nor a sufficient condition for truth. Hence we also see that, and why, Goodman's new, weakened claim that permanent credibility is at least a sufficient condition for truth cannot be sustained.

In light of the entire body of scientific knowledge pertaining to our sensory systems and cognitive mechanisms and to how they acquire and process information about the external world, it is a highly plausible assumption that there are aspects of reality that will forever remain unapproachable to us, even if perhaps not to all possible cognitive subjects. If we are actually aware of our sensory and cognitive limitations, if we have good reason to believe that man is not the measure of all things, then why shouldn't we acknowledge that there could be facts that, in principle, exceed human cognitive faculties? Certainly, this is a sound argument against equating truth and justification under conditions that are epistemically ideal for us.

\section{VII}

My second objection to the epistemic definition of truth proposed by Putnam, the objection I wish to focus on here, is that the definition is circular since its main concept of an epistemically ideal situation can ultimately only be adequately defined with reference to the concept of truth. The truth norm underlies the norms of justification in all their ramifications and refinements. This fact becomes apparent if we center our attention on the concept of 
epistemic justification, and especially if we inquire into the relationship between this concept and the concept of truth. It is indeed possible that some belief is epistemically justified and at the same time actually false. For this reason, truth cannot simply be identified with justification. Thus, the relationship between justification and truth cannot be the relationship of logical implication.

Nonetheless, I do think that there is a conceptual connection between epistemic justification and truth. In agreement with numerous other epistemologists, such as William Alston (1989), Alvin Goldman (1986), Laurence BonJour (1985), and Paul Moser (1989), I insist that, in a certain sense, it is constitutive of justification that it leads to truth, that it counts toward truth. In the final analysis, the essential goal of cognition is to attain true beliefs and avoid false ones, to maximize truth and minimize falsehood. We want our beliefs to represent the world as it really is. The fundamental role of epistemic justification is that of a subjective means to this objective, cognitive goal. Justification helps us to approximate to truth and hence is essentially directed toward it. Accordingly, any belief is epistemically justified for us if and only if we have good reason to believe that it is true. Accepting some belief without good reason would mean disregarding the cognitive goal of truth.

There are varying approaches to explaining more precisely this conceptual connection between epistemic justification and truth. Yet, they all share the view that it is an essential element of the concept of epistemic justification that it is "truth-conducive". This means that the conditions of justification must be such that satisfying them can guarantee that it is extremely probable that a particular belief is true. If attaining justified beliefs did not considerably increase the probability of attaining true beliefs, justification would be insignificant for attaining our primary cognitive goal. Why should we then be concerned about whether our beliefs are justified or not? On the other hand, a conception of justification that includes a connection to truth makes it obvious why justification is considered a desideratum in the search for truth.

Of course, the relevant literature also contains manifold attempts especially from the internalist faction - to explain the concept of justification without using the concept of truth. In such views, the justification of a belief does not consist in the objective probability of its being true, but, on the 
contrary, in how things present themselves to the specific perspective of the human subject. The internalists insist that a belief is justified for some person only if she is consciously aware of the reasons that support the belief or if the reasons are at least cognitively accessible to her. Roderick Chisholm, for example, states the following:

The internalist assumes that, merely by reflecting upon his own conscious state, he can formulate a set of epistemic principles that will enable him to find out, with respect to any possible belief he has, whether he is justified in having that belief. [...] In a word, one need consider only one's own state of mind (Chisholm 1989, 76).

Those who wish to make justification a purely internal matter often advocate a deontological conception of justification according to which a belief is justified if a person having this belief satisfies her intellectual duties or does not violate these. Then, a justified belief is that which is permissible according to the relevant intellectual norms. Yet, a closer look reveals that most advocates of a deontological version of internalism do not go so far as to completely disrupt the connection between justification and truth. For they usually assign a prominent position among our intellectual duties to the obligation of believing what is true and disbelieving what is false. Thus, Chisholm writes:

We may assume that every person is subject to a purely intellectual requirement - that of trying his best to bring about that, for every proposition $\mathrm{h}$ that he considers, he accepts $h$ if and only if $h$ is true (Chisholm 1977, 14).

Although Chisholm does not advocate the idea of truth conducivity, just like other internalists he also takes recourse to truth in order to make the concept of justification comprehensible. He uses the concept of truth to describe the content of our most important intellectual obligations. According to Chisholm, our beliefs are justified if and only if we have exerted the greatest effort to accept them only if they are true. So the theory of epistemic justification does not seem to be able to work without some recourse to the concept of truth.

Of course, there are other scholars, such as Carl Ginet (1975) or John Pollock (1974), who have attempted to characterize epistemic rationality without referring to the concept of truth in any way at all. I do not think that such attempts could have much chance of success. Without taking recourse to the concept of truth they can neither succeed in differentiating epistemic 
justification from other forms of justification, be these moral, legal or pragmatic, nor in determining adequate criteria that would allow for a rational choice between competing rules of justification. But this is not a topic that need be explored in detail here. The crucial point is that those who advocate equating truth and justification under epistemically ideal conditions cannot find support in such attempts to sever the conceptual connection between justification and truth. They cannot find any support here because their entire argument that truth is nothing other than epistemically ideal justification fails if the concept of justification does not involve truth conducivity. For if the concept of justification does not even include a guarantee of the probability that a statement is true, it is obvious that a belief, regardless of how ideally justified it may be, can nonetheless be false. To put it briefly: if the conceptual connection between justification and truth is denied, identifying truth and justification in an epistemically ideal situation becomes totally implausible. But if this close connection is indeed acknowledged then the identification proposed becomes circular.

\section{VIII}

During the last stage of his internal realism, Putnam himself began to admit that an explication of the concept of an epistemically ideal situation is dependent on the concept of truth (cf. Putnam 1988, 115). Nonetheless, he did not believe that this would lead him to a vicious circle. At this point, he asserted that what he meant by stating that truth was idealized justification was not to be interpreted as if the concept of idealized justification were more fundamental than the concept of truth. Putnam now assured us that he had never aimed at a reduction of truth to epistemic concepts. What he really meant is that the concepts of truth and of idealized justification are interdependent concepts. He readily admitted that his error lay in having hitherto emphasized only one side of this interdependence, truth's dependence on justification, and having neglected the other side, justification's dependence on truth. He now wanted to make up for this deficit by stating that determining whether an epistemic situation is ideal depends on whether many diversified statements are true in the situation.

What can we make of Putnam's more recent assertion that truth and idealized epistemic justification are interdependent concepts? I do not wish 
to deny that the acquisition of the concepts of justification and of truth involves mutual dependence. Yet, I do think that there is a significant asymmetry between these two concepts, an asymmetry that cannot adequately be expressed by the handy phrase of "conceptual interdependence". For although an adequate explication of justification is dependent on the concept of truth, an adequate explication of truth does not at all require epistemic concepts. The fact that $p$ is both a necessary and a sufficient condition for $p$ to be true. There is simply no place for an epistemically necessary or sufficient condition of truth. That $p$ is true requires no more than the fact that $p$, and nothing less than this fact will be sufficient.

\section{References}

Alston, William (1989): Epistemic Justification: Essays in Theory of Knowledge, Ithaca: Cornell University Press, 1989.

BonJour, Laurence (1985): The Structure of Empirical Knowledge, Cambridge/MA: Harvard University Press, 1985.

Carnap, Rudolf (1936): "Wahrheit und Bewährung", in: Skirbekk, Gunnar (ed.): Wahrheitstheorien, Frankfurt: Suhrkamp,1977, 89-95.

Chisholm, Roderick (1977): Theory of Knowledge, 2d ed., Englewood Cliffs, N.J.: Prentice-Hall, 1977.

Chisholm, Roderick (1989): Theory of Knowledge, 3d ed., Englewood Cliffs, N.J.: Prentice-Hall, 1989.

Davidson, Donald (1986): "A Coherence Theory of Truth and Knowledge", in: LePore, Ernest (ed.): Truth and Interpretation. Perspectives on the Philosophy of Donald Davidson, Oxford: Basil Blackwell, 1986, 307-319.

Davidson, Donald (1990): "The Structure and Content of Truth", in: Journal of Philosophy 87 (1990), 279-328.

Dummett, Michael (1975): "What is a Theory of Meaning? (I)", in: Guttenplan, Samuel (ed.): Mind and Language, London: Oxford University Press, 1975, 97-138.

Dummett, Michael (1976): "What is a Theory of Meaning? (II)", in: Evans, Gareth; McDowell, John (eds): Truth and Meaning, Oxford: Oxford University Press, 67-137. 
Frege, Gottlob (1919): Der Gedanke. Eine logische Untersuchung, Beiträge zur Philosophie des deutschen Idealismus 1, 58-77, transl. A. M. and A. Quinton as "The Thought: A Logical Inquiry", in: Mind 65 (1956), 289311.

Ginet, Carl (1975): Knowledge, Perception, and Memory, Dordrecht: Reidel, 1975.

Goldman, Alvin (1986): Epistemology and Cognition, Cambridge/MA: Harvard University Press, 1986.

Goodman, Nelson (1951), The Structure of Appearance, Dordrecht: Reidel, 1951.

Goodman, Nelson (1978), Ways of Worldmaking, Indianapolis: Hackett, 1978.

Goodman, Nelson (1980): “On Starmaking”, in: Synthese 45 (1980), 211215.

Goodman, Nelson (1982): "Notes on the Well-Made World", in: Leinfellner et al. (eds): Language and Ontology. Proceedings of the $6^{\text {th }}$ International Wittgenstein Symposion, Wien: Hölder-Pichler-Tempsky, 1982, 31-38.

Goodman, Nelson (1984), Of Mind and Other Matters, Cambridge/MA: Harvard Universtity Press, 1984.

Horwich, Paul (1990): Truth, Oxford: Basil Blackwell, 1990.

Künne, Wolfgang (1993): "Truth, Rightness, and Permanent Acceptability", in: Synthese 95 (1993), 107-117.

Moser, Paul (1989): Knowledge and Evidence, Cambridge: Cambridge University Press, 1989.

Peirce, Charles Sanders (1958): Collected Papers, Cambridge/MA: Harvard University Press, 1958.

Pollock, John (1974): Knowledge and Justification, Princeton: Princeton University Press, 1974.

Putnam, Hilary (1978): Meaning and the Moral Sciences, London: Routledge \& Kegan Paul, 1978.

Putnam, Hilary (1981): Reason, Truth and History, Cambridge: Cambridge University Press, 1981.

Putnam, Hilary (1983): Realism and Reason: Philosophical Papers, Vol. 3, Cambridge: Cambridge University Press, 1983.

Putnam, Hilary (1988): Representation and Reality, Cambridge/MA: MIT Press, 1988. 
Putnam, Hilary (1990): Realism with a Human Face, Cambridge/MA: Harvard University Press, 1990.

Quine, Willard Van (1990): Pursuit of Truth, Cambridge/MA: Harvard University Press, 1990.

Russell, Bertrand (1912): The Problems of Philosophy, Oxford: Oxford University Press, 1912.

Schantz, Richard (1996): Wahrheit, Referenz und Realismus, Berlin \& New York: de Gruyter, 1996.

Schantz, Richard (1999): "The Role of Sensory Experience in Epistemic Justification: A Problem for Coherentism", in: Erkennnis 50 (1999), 177191.

Schantz, Richard (2001a): “Truth and Reference”, in: Synthese 126 (2001), 261-281.

Schantz, Richard (2001b): "The Given Regained, Reflections on the Sensuous Content of Experience", in: Philosophy and Phenomenological Research 61 (2001), 167-180.

Schantz, Richard (2002) (ed.): What is Truth? Berlin \& New York: de Gruyter, 2002.

Scheffler, Israel (1980): "The Wonderful Worlds of Goodman", in: Synthese 45 (1980), 201-209.

Skorubski, John (1988): "Critical Study [of Crispin Wright Realism, Meaning, and Truth, $1^{\text {st }}$ edn.]", in: Philosophical Quarterly 38 (1988), 500-525.

Strawson, Peter (1950): “Truth", in: Aristotelian Society Supplementary Volume 24 (1950), 129-156.

Williams, Michael (1977): Groundless Belief, New Haven: Yale University Press, 1977.

Wittgenstein, Ludwig (1922), Tractatus Logico-philosophicus, London: Routledge, 1922.

Wright, Crispin (1992): Truth and Objectivity, Cambridge/MA: Harvard University Press, 1992. 
